\title{
Familial Occurrence of Silent Thyroiditis
}

\author{
SHIGENORI NAKAMURA, MAKO ISAJI AND MASATOSHI ISHIMORI
}

Department of Internal Medicine, Gifu Red Cross Hospital, Gifu 502-8511, Japan

\begin{abstract}
Two brothers and their mother, who had allergic rhinitis caused by Japanese cedar pollen, developed silent thyroiditis in spring. In addition, these three patients had the same HLA haplotype. Another brother, the father, and the paternal grandmother, who did not have allergic rhinitis caused by Japanese cedar pollen, did not show symptoms of silent thyroiditis. The present study indicates that genetic and/or environmental factors are important in the development of this familial type of silent thyroiditis.
\end{abstract}

Key words: Silent thyroiditis, Allergic rhinitis, Familial occurrence, Japanese cedar pollen

(Endocrine Journal 52: 617-621, 2005)

SPORADIC silent thyroiditis is characterized by transient thyrotoxicosis, sometimes followed by hypothyroidism, and then euthyroidism $[1,2]$. It can also develop in patients treated with amiodarone, interferon- $\alpha$, interleukin-2, and lithium $[1,2]$. Thus, it is suggested that iodine intake and various cytokines can initiate silent thyroiditis [3]. In addition, silent thyroiditis can also develop in patients after the cessation of steroid treatment for rheumatoid arthritis [4], after adrenalectomy in patients with Cushing's syndrome [5, 6], after the administration of gonadotropin-releasing hormone analogues [7], and after viral infections [810]. However, the outbreak of silent thyroiditis (or atypical thyroiditis) has been indicated in few reports $[11,12]$

Here, we report the cases of two brothers and their mother who developed silent thyroiditis in spring. They had allergic rhinitis caused by Japanese cedar pollen.

\section{Methods}

Serum samples were stored at $-20^{\circ} \mathrm{C}$ until they were

Received: April 6, 2005

Accepted: July 25, 2005

Correspondence to: Dr. Shigenori NAKAMURA, Department of Internal Medicine, Gifu Red Cross Hospital, Gifu 502-8511, Japan assayed. Serum free T3 (fT3), free T4 (fT4), and TSH levels were measured by chemiluminescent immunoassay (Chemilumi ACS-FT3, -FT4, and -TSH, Ciba Corning Diagnostics Corp., Medfield, MA); the normal adult reference ranges in our hospital were 3.4-5.7 $\mathrm{pmol} / \mathrm{l}, 11-23 \mathrm{pmol} / \mathrm{l}$, and $0.41-4.09 \mathrm{mU} / 1$, respectively. Anti-thyroglobulin antibodies and anti-thyroid peroxidase antibodies (or anti-microsomal antibodies) were measured by the particle agglutination method (TGPA and MCPA, Fuji Rebio, Tokyo) (normal range: $<1: 100$ ) or by radioimmunoassay (RIA) (TgAb and TPOAb, Cosmic Corp., Tokyo) (normal range: $\leq 0.3$ $\mathrm{U} / \mathrm{ml})$. Serum thyroglobulin (Tg) level was measured by immunoradiometric assay (IRMA) (ThyroglobulinIRMA, Pasteur, Daiichi Radioisotope, Tokyo); the normal range was less than $35 \mu \mathrm{g} / \mathrm{l}$. Twenty-four hour thyroidal uptake of ${ }^{123} \mathrm{I}$ (radioactive iodine uptake, RAIU) was determined by a standard procedure (normal range: $10-40 \%$ ). TSH-binding inhibitor immunoglobulins (TBIIs) were assayed on the basis of the levels of inhibition of ${ }^{125} \mathrm{I}-\mathrm{TSH}$ binding to its receptor (Kodak TRAb kit, Tokyo) (normal range: $<15 \%$ ). Level of serum immunoglobulin E (IgE) against Japanese cedar pollen was measured by chemiluminescent enzyme immunoassay (CLEIA) (Sanofi Diagnostics Pasteur Inc., Chaska, MN) (negative range: $<0.34$ $\mathrm{IU} / \mathrm{ml}$ ). HLA-A, -B, -C, and -DR antigens were determined using the microtoxicity technique. 


\section{Case Report}

An 11-year-old boy (III-a in Fig. 1) and his 8-yearold brother (III-b) were first referred to our hospital in November 1995 for the evaluation of thyroid enlargement. They had a history of allergic rhinitis caused by Japanese cedar pollen. Three years before, thyroid enlargement had been noted in boy III-a by a local physician. At that time, his thyroid functions were normal. In boy III-b, a neck swelling had been noted in the summer of 1995 . Their thyroid functions including their younger brother's (6-year-old, III-c) are shown in Table 1. Boy III-c did not have allergic rhinitis. The thyroid gland was moderately enlarged and rubbery in boys III-a and III-b, but not in boy III-c. The serum TSH level was slightly increased in boy III-b. Tests for antithyroid antibodies and TBIIs were negative in the three brothers. Ultrasonography of the thyroid gland did not reveal hypoechoic lesions in any of the three brothers. Chronic thyroiditis was suspected in boys III-a and III-b. We advised them not to take excessive iodide.

In March 1996, boys III-a and III-b consulted us again for a regular follow-up. They had been treated for allergic rhinitis with a kampo medicine (Tsumura Sho-seiryu-to extract granules for ethical use). They did not develop fever, neck pain, palpitations, excessive sweating, or finger tremor. The size of their thyroid gland did not change. At that time, their serum free T3 and free T4 levels had increased, while their

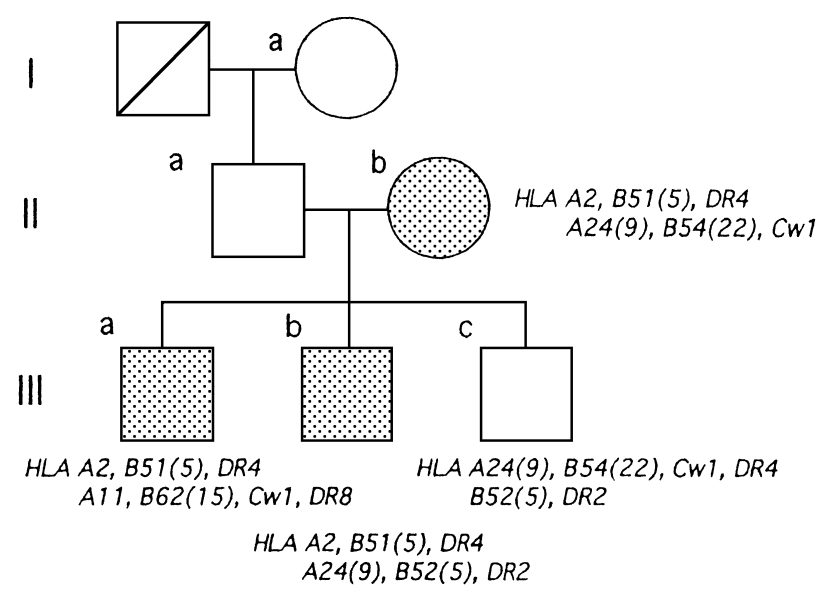

Fig. 1. Family tree of index cases with human leucocyte antigen (HLA). Cases III-a and III-b are index cases. Square refers to a male, circle to a female. Dotted figures are affected family members, open are not-affected. serum TSH level had decreased (Table 2). A diagnosis of silent thyroiditis was made on the basis of the following findings in both patients: ultrasonography did not reveal hypoechoic lesions in their thyroid glands and they showed high serum $\mathrm{Tg}$ concentrations, low RAIUs, and low serum C-reactive protein (CRP) concentrations. In contrast, thyroid functions were normal in boy III-c. In addition, the serum asparate aminotransferase (AST), alanine aminotransferase (ALT), and $\gamma$-glutamyltranspeptidase $(\gamma$-GTP) levels were normal in the three brothers. We also determined the thyroid functions of their father (II-a in Fig. 1), mother (II-b), and paternal grandmother (I-a). The serum free T3 and Tg levels were high and the serum TSH level was low in the mother. On the other hand, thyroid function test results were all normal in the father and grandmother. Tests for antithyroid antibodies were negative in these three family members. The mother had allergic rhinitis caused by Japanese cedar pollen and received mequitazine and azelastine hydrochloride. The changes in the thyroid functions in the three brothers and their mother are shown in Fig. 2. Thyroid functions normalized in boys III-a and III-b, and their mother without any treatment. They did not become hypothyroid during the investigation period. Changes in the serum free T3, free T4, and TSH levels were similar in boys III-a and III-b, and their mother. Serum $\mathrm{Tg}$ level gradually decreased and normalized in the three patients (data not shown). The clinical course indicated that their mother also had silent thyroiditis in the initial phase. Silent thyroiditis did not recur during the subsequent seven years in spring (up to 2003), al-

Table 1. Clinical parameters on the first visit

\begin{tabular}{lccc}
\hline Family members & III-a & III-b & III-c \\
\hline Date & Nov. 95 & Nov. 95 & Nov. 95 \\
Age (yr) & 11 & 8 & 6 \\
Height $(\mathrm{cm})$ & 141 & 123 & 114 \\
Weight $(\mathrm{kg})$ & 39 & 25 & 21 \\
TGPA & $(-)$ & $(-)$ & N.D. \\
MCPA & $(-)$ & $(-)$ & N.D. \\
TgAb & N.D. & N.D. & $(-)$ \\
TPOAb & N.D. & N.D. & $(-)$ \\
fT3 (pmol/l) & 5.8 & 5.6 & 6.9 \\
fT4 (pmol/l) & 13 & 15 & 14 \\
TSH (mU/l) & 2.35 & 5.81 & 2.95 \\
TBIIs $(\%)$ & 3 & 5 & 7 \\
IgE (IU/ml) & $>100$ & 91 & $<0.05$ \\
\hline
\end{tabular}

N.D.: not determined. 
Table 2. Clinical parameters in spring 1996

\begin{tabular}{|c|c|c|c|c|c|c|}
\hline Family members & III-a & III-b & III-c & II-a & II-b & $\mathrm{I}-\mathrm{a}$ \\
\hline Date & Mar. 96 & Mar. 96 & Apr.96 & Apr. 96 & Apr. 96 & Apr.96 \\
\hline Age (yr) & 11 & 8 & 6 & 40 & 38 & 71 \\
\hline TGPA & N.D. & N.D. & N.D. & $(-)$ & $(-)$ & $(-)$ \\
\hline TPOAb & N.D. & N.D. & N.D. & $(-)$ & $(-)$ & $(-)$ \\
\hline $\operatorname{TgAb}$ & $(-)$ & $(-)$ & N.D. & N.D. & $(-)$ & N.D. \\
\hline TPOAb & $(-)$ & $(-)$ & N.D. & N.D. & $(-)$ & N.D. \\
\hline fT3 (pmol/1) & 12.1 & 8.0 & 6.6 & 4.6 & 7.2 & 4.3 \\
\hline fT4 (pmol/1) & 39 & 23 & 17 & 18 & 20 & 16 \\
\hline TSH (mU/l) & $<0.03$ & 0.06 & 1.26 & 0.92 & 0.14 & 2.95 \\
\hline TBIIs (\%) & 2 & 3 & 2 & N.D. & 0 & N.D. \\
\hline $\operatorname{IgE}(\mathrm{IU} / \mathrm{ml})$ & 76 & 34 & $<0.05^{*}$ & 0.18 & 7.4 & $<0.05$ \\
\hline $\operatorname{Tg}(\mu \mathrm{g} / \mathrm{l})$ & $158^{\#}$ & $396^{\#}$ & 40 & 3 & 37 & 14 \\
\hline RAIU (\%) & $2.4^{\#}$ & $3.3^{\#}$ & 16.1 & N.D. & N.D. & N.D. \\
\hline $\mathrm{CRP}(\mathrm{mg} / \mathrm{dl})$ & $<0.24$ & $<0.24$ & $<0.24$ & $<0.24$ & $<0.24$ & $<0.24$ \\
\hline AST (IU/l) & 22 & 28 & 28 & N.D. & N.D. & N.D. \\
\hline ALT (IU/l) & 18 & 16 & 15 & N.D. & N.D. & N.D. \\
\hline$\gamma$-GTP (IU/l) & 14 & 11 & 12 & N.D. & N.D. & N.D. \\
\hline
\end{tabular}

N.D.: not determined.

\#: measured in April 96, *: measured in July 96.
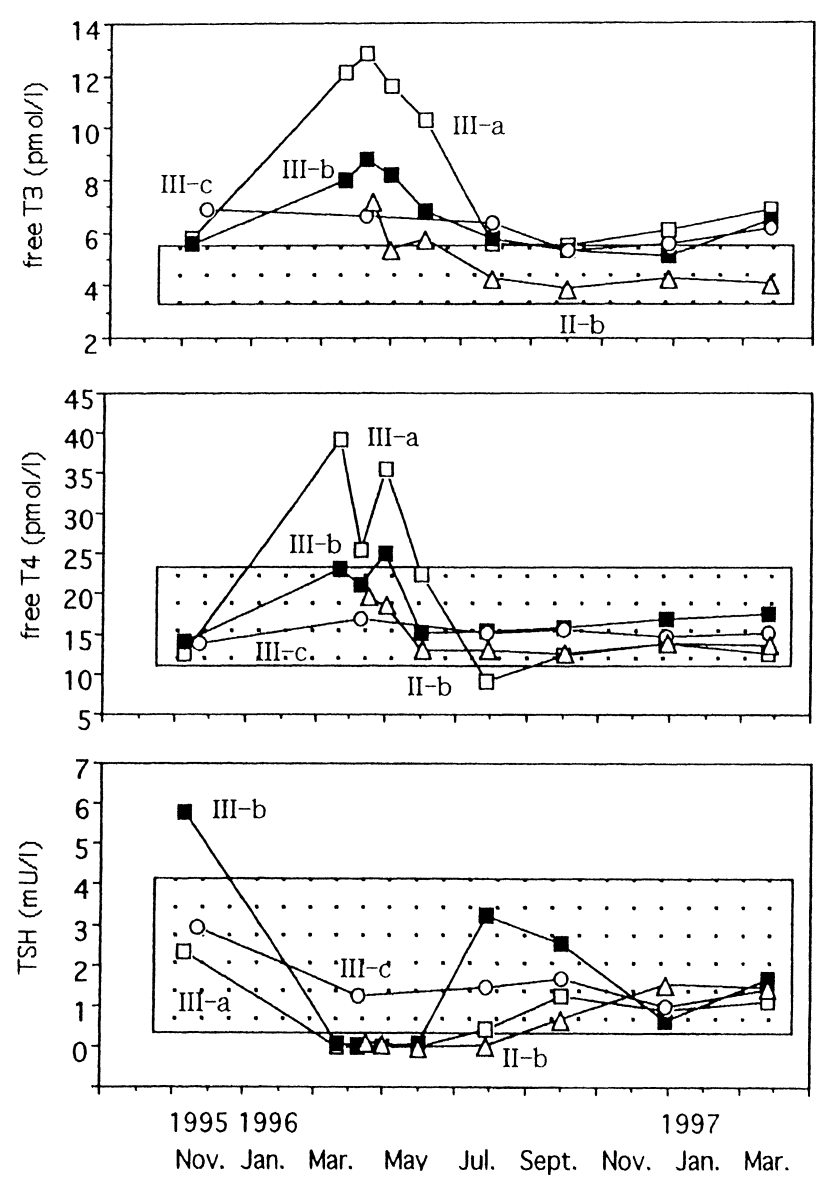

Fig. 2. Changes in thyroid functions in the three brothers (III-a, III-b, and III-c) and their mother (II-b). (see also Fig. 1). though (1) they showed symptoms of allergic rhinitis, such as sneezing, rhinorrhea, and nasal congestion in these years in spring, (2) boys III-a snd III-b were treated for allergic rhinitis with the same kampo in the subsequent two or three years in spring, and (3) they did not move to another place during the investigation period. The level of serum IgE against Japanese cedar pollen was high in the three family members who had silent thyroiditis, while it was normal in the other members. HLA haplotype was also determined in the three brothers and their mother as shown in Fig. 1. HLA haplotype A2, B51(5), DR4 was observed in the three family members who were diagnosed as having silent thyroiditis.

\section{Discussion}

In the present study, we showed that transient thyrotoxicosis developed in the same season in three members of one family. Low RAIUs and high levels of $\mathrm{Tg}$ indicated that thyrotoxicosis was not caused by Graves' disease or the ingestion of exogenous thyroid hormones [13-15], but by destructive thyroiditis such as subacute thyroiditis and silent thyroiditis. Low CRP concentrations and ultrasonograms indicated that silent thyroiditis had developed in the three members. In 1988, Ogura et al. [11] reported that silent thyroiditis 
occurred simultaneously (October) in five staff members of a nursery school. In 1990, de Bruin et al. [12] reported the presence of atypical subacute thyroiditis, which developed in 12 patients, including two family members in the same period (July-September). In both reports, flulike symptoms and liver dysfunction were observed in most of the patients, suggesting that viral infection might be a cause of thyrotoxicosis [8-10]. However, no evidence of a viral infection was obtained in these studies. In contrast, our present patients did not show flulike symptoms and had normal liver function test results.

As shown in Fig. 2, the serum free T3 levels in the three brothers, especially in boy III-c, were somewhat higher than the adult reference range when the serum TSH levels were normal. However, this finding is thought to be of weak diagnostic significance since (1) the upper limit of the child reference range of the serum free T3 level was reported to be higher than that of the adult reference range [16, 17], and (2) the free T3 levels in the three brothers gradually decreased thereafter and finally fell into the adult reference range (data not shown). In addition, a transient decrease in serum free T4 level was observed in boys III-a and III-b in the thyrotoxic phase. This phenomenon was also reported in four patients by de Bruin et al. [12], who stated that the secondary increase in thyroid hormone levels might have been caused by the reactivation of the destructive process.

In the present study, neither anti-Tg antibodies nor anti-TPO antibodies were detected in the three patients. In addition, these antibodies measured by the particle agglutination method were not detected in the five patients in the study by Ogura et al. [11] and 12 patients in the study by de Bruin et al. [12]. Silent thyroiditis is considered a variant form of chronic thyroiditis and many patients with silent thyroiditis have anti-Tg and anti-TPO antibodies in their serum [18, 19]. Retrospectively, serum anti-Tg antibody and anti-TPO antibody levels measured by RIA were determined in 45 patients ( 7 males and 38 females) with sporadic silent thyroiditis who visited our hospital beween January 2000 and November 2004. Seventy-three percent (33 patients) of the patients were positive for anti-Tg antibodies and/or anti-TPO antibodies (anti-Tg antibodies,
11 patients; anti-TPO antibodies, 1 patient; and both, 21 patients). Only 27\% (12 patients) of the patients were negative for these antibodies. Thus, the absence of antithyroid antibodies may be characteristic of such silent thyroiditis as shown in the present and previous studies [11, 12].

The three patients had allergic rhinitis caused by Japanese cedar pollen and had high levels of serum specific IgE against Japanese cedar pollen. Silent thyroiditis developed in the two patients in March and in the other patient (mother) in March or April, when Japanese cedar pollen is heavily disseminated in air in Japan. In contrast, silent thyroiditis did not develop in the other family members who did not have allergic rhinitis caused by Japanese cedar pollen. However, silent thyroiditis did not develop in the subsequent seven years in spring, although they showed an annual recurrence of allergic rhinitis in spring. Concerning the occurrence of silent thyroiditis and allergic rhinitis, Yamamoto et al. [20] reported the recurrence of silent thyroiditis twice a year, namely, in spring and autumn, in a woman with seasonal allergic rhinitis who worked in a flower shop. She had a high serum level of $\operatorname{IgE}$ antibody against almost all pollen antigens such as Japanese cedar and ragweed. However, a correlation between her thyroid function and total or antigenspecific IgE level was not established. In addition, Hidaka et al. [21] reported the recurrence of thyrotoxicosis after an attack of allergic rhinitis in patients with Graves' disease. Therefore, it cannot be completely ruled out that allergic rhinitis caused by Japanese cedar pollen could have had some influence on the development of silent thyroiditis in our present patients.

Our present patients had the same HLA haplotype (A2, B51(5), DR4), as shown in Fig. 1. These results indicated that the genetic background may had played a role in the development of silent thyroiditis in our present patients.

In conclusion, silent thyroiditis developed in three members of one family in the spring who had allergic rhinitis and the same HLA haplotype, indicating that genetic and/ or environmental factors are important in the development of this rare type of silent thyroiditis. 


\section{References}

1. Lazarus JH (1996) Silent thyroiditis and subacute thyroiditis. In: Braverman LE, Utiger RD (eds) The Thyroid (7th ed), Lippincott-Raven Publishers, Philadelphia, 577-591.

2. Pearce EN, Farwell AP, Braverman LE (2003) Thyroiditis. $N$ Engl J Med 348: 2646-2655.

3. Burman KD (2004) Subacute lymphocytic (painless) thyroiditis. www.uptodate.com (version12.3).

4. Maruyama H, Kato M, Mizuno O, Kataoka K, Matsuki S (1982) Transient thyrotoxicosis occurred after cessation of steroid therapy in a patient with autoimmune thyroiditis and rheumatoid arthritis. Endocrinol Jpn 29: 583-588.

5. Haraguchi K, Hiramatsu K, Onaya T (1984) Transient thyrotoxicosis after unilateral adrenalectomy in two patients with Cushing's syndrome. Endocrinol Jpn 31: 577-582.

6. Yamakita N, Sakata S, Hayashi H, Maekawa H, Miura K (1993) Case report: silent thyroiditis after adrenalectomy in a patient with Cushing's syndrome. Am J Med Sci 305: 304-306.

7. Amino N, Hidaka Y, Takano T, Tatsumi K, Izumi Y, Nakata Y (2003) Possible induction of Graves' disease and painless thyroiditis by gonadotropin-releasing hormone analogues. Thyroid 13: 815-818.

8. Morrison J, Caplan RH (1978) Typical and atypical ('silent') subacute thyroiditis in a wife and husband. Arch Intern Med 138: 45-48.

9. Nakamura S, Kosaka J, Sugimoto M, Watanabe H, Shima H, Takuno H (1990) Silent thyroiditis following rubella. Endocrinol Jpn 37: 79-85.

10. Masuno M, Kosaka J, Nakamura S (1991) Silent thyroiditis in an eleven-year-old girl, associated with transient increase in serum IgM and thyroid hormones. Endocrinol Jpn 38: 219-222.

11. Ogura T, Hirakawa S, Suzuki S, Ota Z, Togawa T, Nogami I (1988) Five patients with painless thyroiditis simultaneously developed in a nursery school. Endocrinol Jpn 35: 225-230.

12. de Bruin TW, Riekhoff FP, de Boer JJ (1990) An outbreak of thyrotoxicosis due to atypical subacute thyroiditis. J Clin Endocrinol Metab 70: 396-402.

13. Hedberg CW, Fishbein DB, Janssen RS, Meyers B,
McMillen JM, MacDonald KL, White KE, Huss LJ, Hurwitz ES, Farhie JR, Simmons JL, Braverman LE, Ingbar SH, Schonberger LB, Osterholm MT (1987) An outbreak of thyrotoxicosis caused by the consumption of bovine thyroid gland in ground beef. $N$ Engl $\mathrm{J} \mathrm{Med}$ 316: 993-998.

14. Kinney JS, Hurwitz ES, Fishbein DB, Woolf PD, Pinsky PF, Lawrence DN, Anderson LJ, Holmes GP, Wilson CK, Loshchen DJ, Nordlund HM, Oldfather J, Rodey GE, Stoesz PA, Schonberger LB (1988) Community outbreak of thyrotoxicosis: epidemiology, immunogenetic characteristics, and long-term outcome. Am J Med 84: 10-18.

15. Matsubara S, Itoh M, Tarumi Y, Sato M, Takahara J (1995) An outbreak (159 cases) of transient thyrotoxicosis without hyperthyroidism in Japan. Intern Med 34: 514-519.

16. Cioffi M, Gazzerro P, Vietri MT, Magnetta R, Durante A, D’Auria A, Puca GA, Molinari AM (2001) Serum concentration of free T3, free T4 and TSH in healthy children. J Pediatr Endocrinol Metab 14: 1635-1639.

17. Hubner U, Englisch C, Werkmann H, Butz H, Georg T, Zabransky S, Herrmann W (2002) Continuous agedependent reference ranges for thyroid hormones in neonates, infants, children and adolescents established using the ADVIA Centaur Analyzer. Clin Chem Lab Med 40: 1040-1047.

18. Nikolai TF, Brosseau J, Kettrick MA, Roberts R, Beltaos E (1980) Lymphocytic thyroiditis with spontaneously resolving hyperthyroidism (silent thyroiditis). Arch Intern Med 140: 478-482.

19. Mizukami Y, Michigishi T, Hasimoto T, Tonami N, Hisada K, Matsubara F, Takazakura E (1988) Silent thyroiditis: a histologic and immunohistochemical study. Hum Pathol 19: 423-431.

20. Yamamoto M, Shibuya N, Chen LC, Ogata E (1988) Seasonal recurrence of transient hypothyroidism in a patient with autoimmune thyroiditis. Endocrinol Jpn 35: $135-142$.

21. Hidaka Y, Amino N, Iwatani Y, Itoh E, Matsunaga M, Tamaki H (1993) Recurrence of thyrotoxicosis after attack of allergic rhinitis in patients with Graves' disease. J Clin Endocrinol Metab 77: 1667-1670. 